\title{
CONJUGALIDADE E AIDS: UM ESTUDO SOBRE INFECÇÃO ENTRE CASAIS
}

\author{
Leandro Castro Oltramari \\ Liliane Schuch Otto \\ Universidade do Vale do Itajaí
}

\begin{abstract}
RESUMO: O presente trabalho surgiu a partir de uma pesquisa de conclusão de curso, realizada com o objetivo de identificar a percepção de risco sobre a infecção de HIV/AIDS entre homens e mulheres universitários que vivem em relacionamento de conjugalidade. A pesquisa foi um estudo de caso, que se estruturou através de dez entrevistas, de cunho qualitativo, com cinco homens e cinco mulheres, os quais mantinham, na época da entrevista, relacionamentos de conjugalidade com estabilidade e coabitação. A idade dos entrevistados variou entre 25 e 57 anos. Os resultados demonstraram que homens e mulheres que vivem em regime de conjugalidade possuem dificuldade no tocante à percepção de risco com relação ao HIV, sendo que o tempo de relacionamento é um componente importante presente nas respostas dadas pelos entrevistado(as). Os entrevistados e entrevistadas se consideram com menor possibilidade de contrair o vírus do que outras pessoas, pois confiam nos parceiros.
\end{abstract}

PALAVRAS-CHAVE: AIDS; percepção de risco; conjugalidade.

\section{CONJUGALITY AND AIDS: A STUDY ON THE RISK OF INFECTION AMONG COUPLES WHO COHABIT}

ABSTRACT: This article is the result of a research with the objective of identifying risk perception/awareness of HIV/ AIDS infection among university students living in a conjugal relationship. The research was a case study structured among ten qualitative interviews, whose participants were composed of five men and five women who had, at the time of the interview, steady conjugal relationships and were cohabiting. The age of the participants ranged from 25 to 57. The results showed that men and women who maintain a conjugal relationship have difficulties concerning risk perception of HIV/AIDS infection, and that the length of the relationship is an important factor present in their answers. The interviewees consider themselves of having a lower possibility of being infected than other people, since they trust their partners.

KEYWORDS: AIDS, risk perception, conjugality.

O presente estudo surgiu a partir de pesquisas que demonstram que os índices de infecção pelo HIV têm sido elevados, principalmente entre pessoas com relacionamentos de conjugalidade. Por exemplo, um estudo realizado por Korniblit, e Diaz (2000) mostrou que um número muito grande de jovens faz uso do preservativo com parceiros casuais e no inicio dos relacionamentos, mas o abandonam quando passa a ser estabelecido um relacionamento estável e, dessa forma, passam a adotar outros métodos. Por exemplo, a pílula é, segundo a autora, uma das formas da distância que se estabelece entre o risco de infecção pelo HIV e a percepção sobre ele, pois quando aumenta a confiança entre as pessoas o uso de preservativo diminui.

No Brasil, estimava-se que em 1994, existisse uma mulher infectada para cada 667 habitantes do sexo feminino, sendo que a maioria donas-de-casa ou empregadas domésticas, que foram infectadas através da relação sexual (Barbosa, Villela \& Uziel, 1995). Mas estes dados diminuíram sensivelmente nos anos seguintes e a diferença entre homens e mulheres infectados foi decrescendo até alcançar a marca, em 2004, de dois homens para cada mulher infectada.

Os indicadores do Ministério da Saúde (Brasil, 2004) têm mostrado um crescimento significativo dos números da epidemia entre pessoas heterossexuais, as quais járepresentam cerca de $15,7 \%$ de todos os casos de AIDS no Brasil. Sendo que estes números mudaram significativamente desde o início da epidemia. No ano de 1993, no país, $29,5 \%$ de todos os casos de AIDS estavam ligados à transmissão sexual. Destes, 22,3\% foram diagnosticados entre homossexuais, enquanto os heterossexuais representavam $18 \%$ das pessoas infectadas. No ano de 1997, o número de homossexuais diagnosticados diminuiu para $18,7 \%$, enquanto o número dos heterossexuais elevou-se para $25,6 \%$ dos casos diagnosticados entre pessoas que contraíram o HIV através de relacionamento sexual. No ano de 2002, os homossexuais representavam $16,6 \%$ dos infectados por via sexual, enquanto os heterossexuais representavam, já naquele ano, cerca de $38,6 \%$ das pessoas infectadas por transmissão sexual. Tais dados demonstram uma preocupação com os indicadores de infecção por via sexual entre 
mulheres e homens heterossexuais, mesmo que haja, no momento, uma relativa estabilização dos índices de doentes de AIDS.

Assim sendo, este trabalho procurou compreender qual é a percepção de risco de infecção pelo HIV/AIDS entre homens e mulheres que mantêm relacionamentos de conjugalidade. Esta preocupação tem sido justificada pelo baixo uso de preservativo nesses casos. O motivo do baixo grau de uso está na confiança que os sujeitos depositam um no outro além de sentimentos de familiaridade e de intimidade que surgem rapidamente a partir da formação de um casal (Carvalho, 1998; Korniblit \& Diaz, 2000; Madeira, 1998; Martin, 1997; Monteiro, 1999a, 1999b; Tura, 1998; Westrupp, 1997).

O presente artigo busca compreender o que leva as pessoas a adotarem tais condutas, apesar de, na maioria dos casos, terem informações a respeito do risco que correm. Conforme trabalhos realizados pela equipe de Korniblit e Diaz (2000), existe uma grande discrepância sobre o conhecimento e a efetivação de condutas preventivas nas relações sexuais, em especial com relação a AIDS, e a aceitação efetiva de tais condutas. Este artigo apresentará pesquisas relativas ao campo da saúde coletiva com os principais conceitos utilizados dentro do trabalho. Posteriormente, serão apresentados os procedimentos metodológicos, os resultados da pesquisa e, por fim, as considerações finais e referências bibliográficas.

\section{O surgimento do HIV/AIDS no campo da saúde coletiva}

Em 1986, um comitê internacional recomendou o termo HIV, do inglês "Humam Immunodeficiency Vírus" (Vírus da Imunodeficiência Humana), para denominar o vírus como capaz de infectar humanos. Conforme explicam Batista e Gomes (2000), os principais alvos de ação do HIV são as células brancas do sangue, chamadas linfócitos T CD4+ ou helper (auxiliadores), que são importantes na coordenação e orientação das defesas do organismo (sistema imunológico), sendo considerados os estrategistas no combate aos agressores com os quais entramos em contato. O HIV destrói as células T CD4+ e quando o seu número atinge baixos níveis, devido à progressão da infecção, o sistema imunológico torna-se débil. O resultado é o surgimento de microorganismos, como fungos, vírus, bactérias e parasitas que podem atuar com mais facilidade, causando doenças graves. Tais doenças são chamadas de oportunistas.

Em 1981, com a irrupção da AIDS, grande parte da população mundial começou a sentir-se preocupada e esta preocupação não atingia apenas aqueles infectados pelo vírus, mas todo o conjunto da sociedade. A transmissão sexual do HIV, desde 1980, corresponde a 54\% do total dos casos de AIDS entre homens e mulheres, casos estes notificados pelo Ministério da Saúde. Um dos maiores desafios tem sido, desde então, fazer com que a população utilize o preservativo nas relações sexuais. (Brasil 2000).

Em 1983, o número de pessoas infectadas pelo vírus, segundo a Organização Mundial de Saúde (OMS) era de 4000 casos no mundo. Hoje, sabemos que aproximadamente 40 milhões de pessoas convivem com o HIV. A cada 24 horas mais de 15 mil pessoas continuam a serem infectadas (Zampieri, 2004). Do total de casos registrados desde 1980, os homens aparecem em maior número: são 220.783 com a doença $(71,1 \%)$, contra 89.527 mulheres $(28,8 \%)$.

A principal via de transmissão da doença é a relação heterossexual desprotegida, respondendo por $86,8 \%$ dos casos notificados em mulheres e por $25,7 \%$ dos casos em homens. A segunda via de transmissão mais eficaz tem sido o compartilhamento de seringas entre usuários de drogas injetáveis, que responde por $11,7 \%$ dos casos registrados no grupo feminino e por 22,8\% entre os homens (Brasil, 2004).

Segundo os levantamentos realizados por Korniblit e Diaz (2000) e o Ministério da Saúde (2004), a epidemia vem avançando devido ao fato das pessoas adotarem o uso da camisinha apenas como método contraceptivo e não como estratégia de prevenção da infecção. No lugar do preservativo, as pessoas consideram a fidelidade, a confiança e o conhecimento do parceiro como forma de prevenção. Assim, para quem vive em regime de conjugalidade, conhecer o outro se tornou o método de prevenção mais utilizado para qualquer doença sexualmente transmissível (Korniblit \& Diaz, 2000). Isto acontece segundo as autoras porque, com o passar dos anos, o relacionamento vai se tornando mais confiante, mais seguro, os indivíduos dizem conhecer seus parceiros e o uso do preservativo torna-se dispensável. A partir do momento em que o relacionamento conjugal passa a ser mais duradouro, com maior intensidade, homens e mulheres dão novos sentidos à noção de risco que correm de contraírem uma Doença Sexualmente Transmissível (DST), principalmente a AIDS.

Estudos semelhantes foram realizados no Brasil e, encontraram a mesma relação entre o baixo uso de preservativo e o vínculo afetivo sexual. Em alguns estudos, Monteiro (1999a, 1999b) descreve que adolescentes, meninos e meninas, de uma favela carioca, mesmo sabendo sobre os riscos aos quais estavam expostos por não utilizarem o preservativo, apenas o utilizavam quando não possuíam algum tipo de proximidade afetiva maior com o parceiro. O uso do preservativo tem sido bem aceito para relacionamentos casuais, mas mesmo assim, ocorrem exceções. Porém, torna-se dispensável nos relacionamentos conjugais duradouros. As pessoas justificam essa atitude usando palavras como: confiança, conhecimento, amor, entre outras. 


\section{Método}

A pesquisa foi de cunho qualitativo ao nível de estudo de caso, realizada na Universidade do Vale do Itajaí (UNIVALI). Contou com a participação de dez estudantes da referida instituição, entre 25 e 57 anos de idade, sendo cinco homens e cinco mulheres, todos estavam vivenciando um relacionamento conjugal com coabitação.

Os participantes foram convidados a participar da pesquisa dentro da própria universidade. O instrumento utilizado para coletar os dados foi uma entrevista semi-estruturada, individual e gravada em fita K7, com a devida autorização de todos os participantes. As entrevistas foram realizadas em salas de aula disponíveis da própria UNIVALI. Vale destacar que a pesquisa foi realizada com a aprovação do Comitê de Ética da instituição sob n 076/04.

Foi aplicado um roteiro de entrevista semi-estruturada com as seguintes questões: sexo, idade, tempo de relacionamento, o que a pessoa compreendia por relacionamento conjugal, quais os fatores que considerava mais importante no relacionamento conjugal, quais os maiores problemas enfrentados no seus relacionamento, como percebiam a utilização de preservativo no relacionamento conjugal, como se dá o processo de conhecimento da pessoa para deixar de usar preservativo, o que o(a) levou a usar o preservativo a primeira vez, em que circunstancias percebeu a necessidade de utilizar o preservativo, como percebia o risco da AIDS.

Considerando a teoria de Chizzotti (1998), os dados foram analisados dentro dos recursos do método qualitativo, a análise de conteúdo, que consiste em um processo complexo, não linear, aplicado a um trabalho de redução, organização e interpretação dos dados. O material coletado nas entrevistas foi analisado através da análise de conteúdo do tipo categorial que, segundo Bardin (2000, p.
153), remete-se a uma operação de “[...] desmembramento do texto em unidades, em categorias segundo reagrupamentos analógicos [...]”, conseguindo temas que sejam significativos para explicação do material coletado. As respostas foram separadas e analisadas por categorias, de acordo com os temas centrais relacionados aos objetivos específicos da pesquisa. As categorias foram sendo criadas de acordo com as junções de respostas adquiridas pelos sujeitos da pesquisa.

\section{Análise e interpretação dos dados}

A análise dos dados foi realizada a partir das respostas verbalizadas pelos entrevistados e entrevistadas. Apresentaremos na Tabela 1 os dados dos entrevistados.

A primeira resposta concerne à definição dada por homens e mulheres em relação ao relacionamento conjugal. Foi observado que, para a maioria (seis pessoas, num total de dez), o relacionamento conjugal seria uma ligação de sentimentos. Esta categoria foi criada com respostas que fizeram referência à: afetividade, ao compromisso, à responsabilidade, ao companheirismo, ao respeito, à troca, à ajuda etc. "É o relacionamento entre duas pessoas, onde há pelo menos o nível mínimo de afetividade, de envolvimento, de compromisso, de responsabilidade, um elo, uma ligação" (mulher, 29 anos).

Não aparece, nas entrevistas, a ligação de sentimentos com a questão do amor romântico, aquele que para Giddens (1993, p. 56) “[...] se projeta em dois sentimentos: apóiase no outro e idealiza o outro, e projeta um curso do desenvolvimento futuro."

Outra questão importante identificada na pesquisa foi o fato do relacionamento conjugal estar atrelado à idéia de "viver junto", ou seja, coabitação entre duas pessoas. De acordo com o relato de um participante, "Casamento,

Tabela 1. Sexo, idade, curso freqüentado e tempo de relacionamento dos participantes.

\begin{tabular}{ccccc}
\hline Participantes & Sexo & $\begin{array}{c}\text { Idade } \\
\text { (anos) }\end{array}$ & $\begin{array}{c}\text { Curso que } \\
\text { freqüentava }\end{array}$ & $\begin{array}{c}\text { Tempo de } \\
\text { relacionamento (anos) }\end{array}$ \\
\hline $\mathbf{1}$ & $\mathrm{F}$ & 25 & Psicologia & 5 \\
$\mathbf{3}$ & $\mathrm{F}$ & 52 & Psicologia & 38 \\
$\mathbf{4}$ & $\mathrm{F}$ & 44 & Psicologia & 26 \\
$\mathbf{5}$ & $\mathrm{F}$ & 29 & Administração & 9 \\
$\mathbf{6}$ & $\mathrm{M}$ & 30 & Administração & 8 \\
$\mathbf{7}$ & $\mathrm{M}$ & 34 & Administração & 17 \\
$\mathbf{8}$ & $\mathrm{F}$ & 27 & Psicologia & 8 \\
$\mathbf{9}$ & $\mathrm{M}$ & 57 & Psicologia & 40 \\
10 & $\mathrm{M}$ & 38 & Administração & 3 \\
\hline
\end{tabular}


não só casamento propriamente dito no papel. Hoje em dia pouca gente casa. Então relacionamento conjugal pode ser visto como um convívio diário." (homem, 30 anos).

Também foi observado o relacionamento conjugal vinculado à idéia de família, deixando claro, a sua importância na sociedade e a divisão de papéis que ainda prevalece em alguns casos na sociedade moderna. Um dos participantes relatou que "Relacionamento conjugal para mim é família, compromisso, afeto, é conviver ao lado de quem você ama. Dividir suas tristezas e alegrias com alguém" (homem, 28 anos). Vale ressaltar que embora haja mudanças dentro das construções sobre família e a forma como esta se apresenta, ainda assim ela é uma importante referência para entrevistados e entrevistadas. Ainda apareceram nas respostas, com menor freqüências, questões atreladas à: administração do relacionamento, à monogamia, à confiança e ao contrato sexual.

A questão que versava sobre o uso de preservativos nos relacionamentos conjugais foi fundamental para esta pesquisa. A maioria das respostas vinculou a confiança a uma forma de relacionar-se com o parceiro ou parceira, fazendo com que estes se encontrassem, de alguma forma, seguros em relação ao risco de infecção pelo HIV. Vejamos um exemplo de uma mulher de 44 anos:

Eu acho que é algo que devia de ser tá, com certeza. Eu tenho uma relação de confiança com o meu marido, que eu sei onde ele está, eu sei o tempo todo. Minhas três filhas trabalham com ele, a gente fala muito sobre isso. Eu não tenho dúvida realmente. Essa relação de confiança eu construí, a gente construiu, mas quando eu tiver qualquer dúvida eu vou usar camisinha. Se eu sentir que alguma coisa aconteceu, que eu perceber, eu estou atenta, além de fazer exame periodicamente (mulher, 44 anos).

Os entrevistados, na sua maioria, utilizam o preservativo para evitar uma gravidez indesejada, também relacionando-o como uma forma de prevenção das doenças sexualmente transmissíveis. Contudo relataram não o utilizarem com seus parceiros fixos, devido à confiança que adquiriam, um em relação ao outro, com o passar do tempo. Afirmam, ainda, que utilizariam caso mantivessem relacionamentos extraconjugais.

Segundo os dados do Ministério da Saúde (Brasil, 2004), no momento em que um relacionamento conjugal é estabelecido, tanto homens quanto mulheres dão novos sentidos para o uso do preservativo. E não foi diferente na pesquisa realizada. O preservativo passou a ser visto como uma prevenção da gravidez indesejável. Ele era ao mesmo tempo usado para evitar gravidez e doenças, mas foi deixado quando a construção do vínculo da confiança se estabelecia entre o casal.

O vínculo de confiança esteve atrelado ao que Matos (2000) chamou de códigos comuns. A utilização do pre- servativo não esteve implícita nesses códigos, pois, no momento em que a confiança se estabelece, inicia-se um território mútuo entre os parceiros, surge uma cumplicidade e o preservativo não tem mais a função de prevenir riscos, que passam a não existir para o casal. Uma entrevistada relata que:

Ora, era o ideal né que todo relacionamento conjugal a gente usasse, mas na prática não é o que acontece, porque você já está algum tempo, você já confia, já sabe do horário da pessoa. É, o ideal seria, porém eu acho que na prática não acontece (mulher, 29 anos).

Algumas pessoas perceberam o preservativo como um elementoimportante para os relacionamentos extraconjugais, ou seja, quando não se conhece a pessoa com quem se relaciona, uma categorização que elabora a idéia de um "outro", que se faz mais perigoso que as pessoas conhecidas. Este "outro" acaba muitas vezes tomando um caráter de uma prevenção simbólica, pois enquanto se preocupam com as "outras pessoas" fazem um isolamento "imaginário" do risco de contrair HIV. Portanto, é comum, a AIDS ser atribuída a pessoas de "outros" grupos dos quais os sujeitos não fazem parte, havendo, assim, um distanciamento de seu grupo dos riscos de contrair a doença (Avi, 2000; Joffe, 1998a; 1998b; Knauth, 1997).

Com relação ao que os entrevistados compreendiam sobre confiança, o que conseguimos foram respostas que atrelam a confiança ao sentido de acreditar no parceiro. Uma das entrevistadas nos deu a seguinte resposta:

É você acreditar no que essa pessoa diz. É na sinceridade que cabe nessa relação, tanto para estados bons, como para estados ruins. É a disponibilidade e flexibilidade para essa abertura para essa confiança, para esse diálogo (mulher, 29 anos).

Para os homens entrevistados, a confiança apareceu de forma um pouco diversa daquelas apresentadas pelas mulheres. Para eles, a confiança surgiu no sentido de conhecer o outro, como, por exemplo, revelado na fala de um dos entrevistados, "Olha confiar é tu conhecer. A confiança vem com o conhecimento. Você vai conhecendo as coisas e vai confiando nas coisas" (homem, 34 anos). Podemos compreender estas questões a partir do que foi apresentado por Matos (2000), que revela que, a partir do momento que o encontro é dado entre os parceiros, a relação se inicia com a criação de um vínculo de confiança, sobretudo através da troca de conhecimentos cognitivoafetivos de um sobre o outro. A confiança cria no casal um sentimento de segurança, de pertencer a alguém, que será incapaz de prejudicar o próprio parceiro(a).

A confiança foi também atrelada, tanto por homens quanto por mulheres, ao sentido de contrato, quando os parceiros possuem um contrato que já está implícito na relação. Existe uma grande dificuldade das pessoas em conceituar confiança, pois cada qual parte de um conceito 
moral, pois se sabe que ela existe no relacionamento, faz parte dele, e, portanto, não é necessário negociá-la ou mesmo discuti-la.

Por último, levantou-se a percepção de homens e mulheres sobre o risco de contrair o HIV. Os resultados foram bastante variados. Quatro entrevistados, entre eles dois homens e duas mulheres, responderam que percebiam seus riscos apenas em uma transfusão de sangue. Tanto homens quanto mulheres, em sua maioria perceberam pouco ou quase nenhum risco de contrair o vírus. Essa percepção de afastamento do risco foi aumentando de acordo com o tempo de relacionamento. "Não acredito que posso ter algum risco dentro do meu relacionamento". (mulher, 52 anos, relacionamento de 38 anos). "O meu risco de contrair a Aids: Eu diria só se fosse por meio que ainda não estão muito claros, ou seja, por meios que não os conhecidos, senão eu não vejo que posso ter risco". (homem, 57 anos, 40 anos de relacionamento).

Pode-se dizer que as afirmações acima estão diretamente relacionadas à questão da confiança que os casais criaram no relacionamento e a construção da segurança entre ambos. É muito difícil o casal perceber-se vulnerável ao risco, principalmente quando mantêm um relacionamento de longo tempo. O problema da infecção pelo HIV parece estar muito longe deles. Observando as respostas como um todo, mais homens do que mulheres se percebem com pouco ou nenhum risco de contaminação. Os homens geralmente se percebem sem probabilidade de infectarem-se com alguma doença, o homem se concebe como uma fortaleza, como o ser masculinizado, que pode tudo (Zampieri, 2004). Já as mulheres percebem o risco mais perto de si. "O meu risco: Olha basta transar que tem risco. É igual fez sexo: pode ter filho. Se você não usar camisinha está correndo risco sempre" (mulher, 29 anos).

Um fator bem importante que apareceu nesse conjunto de respostas foi às justificativas que as pessoas utilizaram ao revelar não correrem risco. Por exemplo, foram citadas formas como o controle sobre a administração do cotidiano do companheiro ou companheira, como forma de controlar o comportamento dos cônjuges. Ou seja, os parceiros(as) se colocam sem risco, ou com pouco risco, porque dizem "conhecer" as rotinas e horários do cônjuge, aonde o parceiro vai durante o dia, o que faz, onde está naquele determinado momento etc. Isto acontece porque, segundo Zampieri (2004), a infidelidade é um dos assuntos mais difíceis de serem abordados em pesquisas. Os casais geralmente não assumem uma possível traição. $\mathrm{Ou}$ seja, a quebra dessa confiança é sempre vista como remota. Mas, os números da infecção pelo HIV nos relacionamentos conjugais demonstram o quanto isto é falho, pois eles continuam subindo a cada ano.

As respostas demonstraram que tanto os homens quanto as mulheres participantes da pesquisa identificaram al- guns segmentos da população como tendo maiores riscos de infecção pelo HIV. Em primeiro lugar, foi destacado um maior risco para pessoas que utilizavam drogas, pois estas podem realizar comportamentos ligados à não proteção da própria vida, ou seja, a realização de comportamentos sem consciência de prevenção. Uma resposta de um entrevistado elucida o que apresentamos agora: "Drogas, principalmente, porque a droga te leva a sexo sem limites, sem prevenção" (homem, 30 anos). A droga, assim, foi vista como a causadora da irresponsabilidade, da perda da razão, da perda dos limites etc. De alguma forma, estas percepções possuem fundamento, pois pesquisas realizadas por Korniblit e Diaz (2000), sobre o uso do preservativo, mostraram que o álcool é uma droga que faz com que os sujeitos que a ingerem não façam mais uso do preservativo.

Um outro importante meio de infecção da AIDS, segundo os entrevistados, foram as relações sexuais sem uso de preservativos. Aqui pode ser citado o que Korniblit e Diaz (2000) chamaram de "Lógica da rejeição ao preservativo". Esta lógica revela que o preservativo é negado como forma de reafirmação do relacionamento afetivo amoroso. Logo uma pessoa não tem a possibilidade de utilizar o preservativo dentro de um relacionamento com quem ama. Os participantes apóiam seus argumentos a favor de não utilizar o preservativo por causa dos mitos mais freqüentes, como a diminuição do prazer ou ainda experiências negativas que ocorreram durante o seu uso. Existem muitos mitos sobre uso de preservativo entre adolescentes e muitos deles também entre homens adultos. Muitos deles acreditam que o uso do preservativo gera menos prazer ou, ainda, que a ereção pode ser diminuída ao colocá-lo. A negociação mostra-se ainda um problema, pois muitas pessoas temem acabar com a confiança do parceiro(a) na hora de pedir que faça uso do preservativo (Monteiro, 1999a, 1999b).

Por fim, nas respostas surgiram o medo da transmissão do HIV por meio da transfusão sangüínea. Os entrevistados citaram que é preciso ter cuidado ao realizar qualquer operação, as quais devem ser feitas com muita segurança. Outro ponto que citaram foi à necessidade de exigir sempre seringas descartáveis, utilização de luvas, também descartáveis, e objetos sempre bem esterilizados, além de evitar contato com o sangue de outras pessoas, das quais não se sabe o diagnóstico.

\section{Considerações Finais}

O que podemos concluir com este estudo preliminar, realizado com um número limitado de dez pessoas, acadêmicos da Universidade do Vale do Itajaí, do Campus IV é que tal tema é de difícil abordagem, pois discuti-lo é colocar em pauta uma prática que muitas vezes os casais ainda não perceberam entre eles. 
Os resultados apontam que os homens e as mulheres têm percepções diferentes sobre o risco da AIDS, e que muitos não se consideram membros dos grupos de risco, idéia essa que já deveria ter sido descartada. Ainda existe uma concepção disseminada entre os participantes que os fazem acreditar em uma perpetuação da idéia de grupos de risco que os fazem estar, na compreensão deles, isentos desta vulnerabilidade.

Assim, os participantes acreditam estarem seguros frente a esta epidemia. $\mathrm{O}$ tempo de relacionamento também modifica a percepção de risco, tanto em homens como em mulheres. Acredita-se que no momento que a relação é estabelecida, os corpos tornam-se um só e os riscos desaparecem, e que os parceiros são pessoas seguras e confiáveis.

A confiança, como já vem aparecendo em outras pesquisas, também apareceu como ponto forte de segurança no relacionamento. Muitos acreditam que a confiança pode "imunizar" contra a infecção pelo HIV. O relacionamento conjugal é construído sobre a forte segurança do confiar e acreditar no outro. E isto é criado através de determinadas estratégias como, por exemplo, no relacionamento conjugal a confiança está pautada sobre o controle que um parceiro tem sobre as rotinas e horários do outro (a). $\mathrm{O}$ sujeito passa a conhecer os horários, sabe onde ele está e o que faz durante todo o dia. Esta administração também pode ser vista como confiar no parceiro e ter conhecimento de todos os seus passos.

Neste estudo, o relacionamento conjugal apareceu como uma ligação de sentimentos: afeto, compromisso, cumplicidade, dialogo, etc. Embora tenham pesquisas (Barbosa et al., 1995; Korniblit \& Diaz, 2000) que revelam o argumento do amor como uma causa da não utilização do preservativo como forma de prevenção, esta palavra (amor) não foi observada nos relatos das pessoas pesquisadas. Aqui podemos citar o caráter de mudança nas relações afetivosexuais que Giddens (1993) já havia relatado em seu estudo.

Um outro aspecto importante apresentado no estudo foi a não utilização do preservativo nos relacionamentos conjugais. Esse, quando utilizado, esteve atrelado apenas como método contraceptivo.

Portanto, para as intervenções futuras na área da saúde coletiva, fica aqui uma questão a ser pensada, a necessidade de uma mudança de comportamento para a prevenção entre estes casais, mas para isto é preciso que se mudem as práticas e comportamentos sexuais (Zampieri, 2004) É necessário que o casal pense alguns vetores da construção social da masculinidade, da feminilidade para a construção de uma outra forma de conjugalidade.

\section{Referências}

Avi, G. D. S. (2000). Informação técnica não basta: as representações sociais da AIDS em profissionais de saúde. Dissertação de
Mestrado não - publicada, Programa de Pós-graduação em Psicologia Social e da Personalidade, Pontifícia Universidade do Rio Grande do Sul. Porto Alegre, RS.

Barbosa, R. M., Villella, W. V. \& Uziel, A. P. (1995). Entre a vontade e a necessidade: negociação sexual em tempos de Aids. Sexualidade e Saúde Coletiva (RJ), 5(1), 99-107.

Bardin, L. (2000). Análise de conteúdo. Lisboa: Edições 70.

Batista, R. S. \& Gomes, A. P. (2000). AIDS: conhecer étransformar. Petrópolis, RJ: Vozes.

Brasil-Ministério da Saúde (2004). Boletim Epidemiológico, 2004. Retrieved on 18/06/2004 from http://www.aids.gov.br

Brasil - Ministério da Saúde (2000). Sexo e relacionamento. Negociação do preservativo, 2000. Retrieved on 14/08/2003 from http://www.aids.gov.br

Carvalho, M. R. (1998). Eu confio, tu prevines, nós contraímos: uma (psico)lógica (im)permeável à informação? In M. Madeira \& D. Jodelet (Eds.), Aids e representações sociais: à busca de sentidos (pp. 89-94). Natal: EDUFRN.

Chizzotti, A. (1998). Pesquisa em ciências Humanas e sociais. São Paulo: Cortez.

Giddens, A. A. (1993). A transformação da Intimidade: Sexualidade, Amor e Erotismo nas Sociedades Modernas. São Paulo: Editora da Universidade Estadual Paulista.

Joffe, H. (1998a). “Eu não”, “o meu grupo não”: representações sociais transculturais da aids. In P. A. Guareschi \& S. Jovchelovitch (Eds.), Textos em representações sociais (pp. 297-322). Petrópolis, RJ: Vozes.

Joffe, H. (1998b). Degradação, desejo e “o outro”. In A. Arruda (Ed.), Representando a alteridade (pp.109-128). Petrópolis, RJ: Vozes.

Knauth, D. R. (1997). O vírus procurado e o vírus adquirido: a construção da identidade entre mulheres portadoras do vírus daAIDS. Revista de Estudos Feministas, 2, 291-303.

Korniblit, A. L. \& Diaz, A. M. M. (2000). Las “lógicas" del amor en relación con la prevención del contagio de VHI/sida. Acta Psiquiátrica da América Latina Buenos Aires, 46(1), 23-32.

Madeira, M. C. (1998). A confiança afrontada: representações sociais da Aids para jovens. In M. Madeira \& D. Jodelet (Eds.), Aids e Representações sociais: à busca de sentidos (pp. 47-73). Natal: EDUFRN.

Martin, D. (1997). Mulheres e Aids: uma abordagem antropológica. Revista USP, 33, 89-101.

Matos, M. (2000). Reinvenções do Vínculo Amoroso. Cultura e Identidade de Gênero na Modernidade Tardia. Belo Horizonte: Ed. UFMG; Rio de Janeiro: IUPERJ.

Monteiro, S. (1999a). Aids e proteção: a visão de jovens de um bairro popular. Revista de Estudos Feministas, 7, 72-88.

Monteiro, S. (1999b). Aids, sexualidade e gênero: a lógica da proteção entre jovens de um Bairro Popular Carioca. Tese de Doutorado não-publicada, Programa de Pós-graduação em Saúde Pública, Fundação Osvaldo Cruz. Rio de Janeiro, RJ.

Tura, L. F. R. (1998). A aids, o preservativo e a prevenção. [Resumo]. In Jornada internacional sobre representações sociais: teoria e campo de aplicação (p. 38), Natal, RN.

Westrupp, M. H. B. (1997). Práticas sexuais de mulheres de parceiros infectados pelo HIV: contribuições acerca de cadeia epidemiológica da transmissão do HIV/AIDS. Tese de Doutorado não-publicada, Programa de Pós-graduação em Filosofia da Enfermagem, Universidade Federal de Santa Catarina. Florianópolis, SC. 
Zampieri, A. M. F. (2004). Erotismo, sexualidade, casamento e infidelidade. Sexualidade conjugal e prevenção do HIV e da Aids. São Paulo: Ed. Agora.

Leandro Castro Oltramari. Professor da Universidade do Vale do Itajaí, Doutorando em Ciências Humanas/ UFSC, Mestre em Psicologia/UFSC. Endereço para correspondência: Rua Antonio Schoroder, 103 apt. 302, Barreiros - São José, CEP: 88110-400

leandro@cfh.ufsc.br
Liliane Schuch Otto. Bacharel em Psicologia/UNIVALI. lilianeschuch@bol.com.br

\section{Conjugalidade e AIDS: um estudo} sobre infecção entre casais

Leandro Castro Oltramari e Liliane Schuch Otto Recebido: 09/12/2005

$1^{a}$ revisão: 30/06/2006

Aceite final: 08/08/2006 